\title{
The shikimic acid: an important metabolite for the Aglianico del Vulture wines
}

\author{
Pasquale Tamborra, ${ }^{1}$ Dina Bolettieri, ${ }^{2}$ Michele Latorraca, ${ }^{2}$ Michela Tamborra, ${ }^{1}$ \\ Fiorella Paradiso, ${ }^{2}$ Michele Savino' \\ ${ }^{1}$ Consiglio per la Ricerca e la Sperimentazione in Agricoltura - Unità di Ricerca per l'Uva \\ da Tavola e la Vitivinicoltura in Ambiente Mediterraneo - Cantina Sperimentale, Barletta \\ (BAT); ${ }^{2}$ Scuola di Scienze Agrarie, Forestali, Alimentari ed Ambientali, Università della \\ Basilicata, Potenza, Italy
}

\begin{abstract}
Shikimic acid is a precursor for the biosynthesis of aromatic amino acids and flavonoids (anthocyanins, tannins and flavonols). In the pharmaceutical industry, it is obtained by extraction of star anise from China, and at a yield of 3-7\% it is used for the production of antiviral drug, e.g. oseltamivir. Unlike flavonoids which are only present in the grape skins, shikimic acid is present in the juice together with hydroxycinnamil tartaric acids (caffeic, ferulic and p-coumaric acid). Therefore, their content in white wines may not be negligible and their presence may explain the epidemiological studies that showed a reduced incidence of cardiovascular diseases also in people with moderate white wine consumption. The content of shikimic acid has been used to characterize wines. In southern Italy it has been used to distinguish Aglianico grape, which holds medium-high content, from Negroamaro, Primitivo and Uva di Troia grapes who have rather lower levels. It could be useful also to distinguish Fiano di Avellino (high value) from Fiano Minutolo (low value). However, results of a recent work showed that the shikimic acid content decreases significantly during the ripening of the grapes and therefore its content in wine is strongly influenced by the harvest period. Finally, in a recent paper it was highlighted the increase in shikimic acid content at the end of fermentation in an Aglianico del Vulture wine, produced in the area of Rapolla (PZ, Italy) municipality during the 2013 harvest. These last experimental results explain why the values of shikimic acid were lower in
\end{abstract}

Correspondence: Michele Savino, Consiglio per la Ricerca e la Sperimentazione in Agricoltura - Unità di Ricerca per l'Uva da Tavola e la Vitivinicoltura in Ambiente Mediterraneo - Cantina Sperimentale, via Vittorio Veneto 26, 76121 Barletta (BAT), Italy. Tel.: +39.0883.521346.

E-mail: michele.savino@entecra.it

Key words: ripening, shikimic acid, varietal marker.

Conference presentation: Meeting on Environmental Sustainability and Food Security, Potenza, Italy, 2014.

Received for publication: 21 July 2014.

Revision received: 7 November 2014.

Accepted for publication: 8 November 2014.

(C) Copyright P. Tamborra et al., 2014

Licensee PAGEPress, Italy

Italian Journal of Agronomy 2014; 9:615

doi:10.4081/ija.2014.615

This article is distributed under the terms of the Creative Commons Attribution Noncommercial License (by-nc 3.0) which permits any noncommercial use, distribution, and reproduction in any medium, provided the original author(s) and source are credited. grapes and surprisingly higher in wines produced in the 2011 and 2012 harvest.

\section{Introduction}

The shikimic acid is a biosynthetic precursor of the aromatic amino acids such as phenylalanine and tyrosine, and flavonoids (tannins, anthocyanins and flavonols). In the pharmaceutical industry, it is obtained from Chinese star anise with a yield of 3-7\% of shikimic acid and it is used for the production of the antiviral oseltamivir.

In contrast to the flavonoids (anthocyanins, flavonols, tannins) present only in the skins of grapes, shikimic acid is present also in the juice along with the hydroxycinnamoyl tartaric acids (caffeic, paracoumaric and ferulic). Consequently, their content in white wines cannot be negligible and their presence may explain the epidemiological studies that have shown that the intake of white wine in moderate doses provides a reduced incidence of cardiovascular diseases in humans. Several studies have highlighted the biological properties of shikimic acid as an antiviral (Giovannini et al., 2008), anti-inflammatory (El-Seedi et al., 2003), inhibitor of platelet aggregation induced by ADP and collagen (Ma et al., 2000) and the ability to prevent the brain damage after focal ischemia-induced thrombosis (Ma et al., 1999).

The amount of shikimic acid present in wines ranges from a few milligrams in the case of Pinot to $50 \mathrm{mg} / \mathrm{L}$ in Chardonnay and Trebbiano Toscano (Versini et al., 2003), although some wines has displayed higher values that exceed $100 \mathrm{mg} / \mathrm{L}$. In Germany, the content of shikimic acid was used as a parameter to discriminate typical monovarietal Pinot wines purchased from Italy. In same case, Germany has dismissed a batch of Pinot wine with greater quantities of shikimic acid, in comparison to the amount considered normal for the variety. However, later, it was highlighted that a rather large variability of the content of shikimic acid is possible in Pinot: from a few milligrams per litre up to $35 \mathrm{mg} / \mathrm{L}$. In southern Italy it has been used to distinguish Aglianico grape, which holds medium-high content, from Negroamaro, Primitivo and Uva di Troia grapes who have rather lower levels (Tamborra and Esti, 2010). It could be useful also to distinguish Fiano di Avellino (high value) from Fiano Minutolo (low value) (Tamborra et al., 2009). However, results of a recent work (Tamborra et al., 2012) showed that the shikimic acid content decreases significantly during the ripening of the grapes and therefore its content in wine is strongly influenced by the harvest period. Finally, in a recent paper (Paradiso et al., 2014) it was highlighted the increase in shikimic acid content at the end of fermentation in an Aglianico del Vulture wine, produced in the area of Rapolla (PZ, Italy) municipality during the 2013 harvest. These last experimental results explain why the values of shikimic acid were lower in grapes and surprisingly higher in wines produced in the 2011 and 2012 harvest. In this paper, we present the results of several studies conducted on the shikimic acid content in the grapes and wines. 


\section{Materials and methods}

The analysis of organic acids present in grapes and wines is easily carried out by isocratic high-performance liquid chromatography (HPLC) using a Synergi 4 u Hydro-RP 80 A column (size $250 \times 4.60 \mathrm{~mm}$ ) of Phenomenex (Torrance, CA, USA) and phosphoric acid solution (1 $\mathrm{mL}$ of $85 \% \mathrm{H}_{3} \mathrm{PO}_{4}$ in $1 \mathrm{~L}$ of water for HPLC) as mobile phase with flow of the $0.7 \mathrm{~mL} / \mathrm{min}$. The determination of small amounts of shikimic acid is facilitated by its high molar extinction coefficient at the wavelength of $210 \mathrm{~nm}$.

\section{Results and discussion}

The results of the chemical analysis carried out on grapes and wines object of our experimentations, has shown that the content of shikimic acid is extremely variable, as shown in the Figure 1, ranging from a few $\mathrm{mg} / \mathrm{L}$ to over $50 \mathrm{mg} / \mathrm{L}$ in order to variety.

In Table 1 are reported the average values of shikimic acid in relation to the different vintages and training systems.

In order to control the kinetics relative to the content of shikimic acid during maturation, 9 varieties of white grapes and 9 of black grapes, coming from the experimental vineyard Lamarossa of Rutigliano (BA), were monitored during the 2011 harvest.

Table 2 shows that the shikimic acid decreases significantly during the ripening of the grapes and therefore its content in wines depends on the time of harvest. However, it is important the dependence of the shikimic acid content from variety: lower in Moscato b., Moscatello b., Minutolo b., Sangiovese n., Uva di Troia $n$. and higher in Bombino b., Pecorino b., Aglianico $n$.

Even the different training systems (simple curtain, unilateral and bilateral cordon, unilateral and bilateral Guyot) have a certain influence on the content of shikimic acid. In these screenings it is possible to note the higher values of shikimic acid of wines from Cabernet Sauvignon in comparison to those from other cultivars (Table 3).

\section{Shikimic acid in Aglianico del Vulture}

Aglianico del Vulture has medium-high contents of shikimic acid (20-30 mg/L), however we found a very high value $(96 \mathrm{mg} / \mathrm{L})$ in a 2011 Aglianico wine, obtained in a vineyard of Rapolla (PZ, Italy) municipality with $3.94 \mathrm{~g} / \mathrm{L}$ of malic acid at the date of 8 March 2012 .

During the harvest in 2012, we compared Aglianico del Vulture of the same vineyard of Rapolla with Aglianico del Vulture of municipality of Venosa (PZ, Italy), that is from different protected designation of origin production area, detecting shikimic acid contents both in grapes and wines. The content of shikimic acid detected in grapes were $34 \mathrm{mg} / \mathrm{L}$ for Venosa and $17 \mathrm{mg} / \mathrm{L}$ for Rapolla. But the content of shikimic acid of wines (Table 4) were surprisingly very different: $29 \mathrm{mg} / \mathrm{L}$ for Venosa and $113 \mathrm{mg} / \mathrm{L}$ for Rapolla. This last data is very close to the value of the previous year (96 mg/L).

Also the content of succinic acid, an acid produced during alcoholic fermentation, is twice that of wine of Venosa.

Furthermore, during the vintage 2013 it was monitored the organic

Table 1. Shikimic acid contents in different years.

\begin{tabular}{lccc} 
Variety & Vintage & Average \pm CV\% $(\mathrm{mg} / \mathrm{L})$ & N. of sample \\
Primitivo & 2005 & $11.1 \pm 13.6$ & 5 \\
Primitivo & 2006 & $15.5 \pm 18.6$ & 9 \\
\hline Primitivo & 2008 & $6.9 \pm 10.7$ & 23 \\
Negroamaro & 2006 & $10.7 \pm 6.8$ & 17 \\
\hline Negroamaro & 2008 & $4.8 \pm 17.2$ & 38 \\
Negroamaro & 2009 & $4.4 \pm 11.4$ & 27 \\
\hline Malvasia n. & 2006 & $21.9 \pm 8.2$ & 7 \\
Montepulciano & 2006 & $23.5 \pm 7.7$ & 9 \\
\hline Cabernet $S$. & 2005 & $78.7 \pm 6.1$ & 5 \\
\hline
\end{tabular}

Table 2. Evolution of shikimic acid content $(\mathrm{mg} / \mathrm{L} \pm \mathrm{CV} \%)$ during ripening in different varieties.

\begin{tabular}{|c|c|c|c|c|}
\hline \multirow[t]{2}{*}{ Variety } & \multicolumn{4}{|c|}{ Sampling } \\
\hline & Aug 20 & Aug 31 & Sep 13 & Sep 19 \\
\hline Moscato b. & $5.5 \pm 7.4$ & $2.6 \pm 4.6$ & $1.9 \pm 5.6$ & $1.3 \pm 8.9$ \\
\hline Moscatello $b$. & $6.4 \pm 12.3$ & $3.3 \pm 8.8$ & $1.3 \pm 12.5$ & $1.6 \pm 6.6$ \\
\hline Grillo $b$. & $10.3 \pm 8.7$ & $9.0 \pm 6.5$ & $4.8 \pm 7.6$ & $3.9 \pm 11.1$ \\
\hline Montepulciano $n$. & $26.7 \pm 5.5$ & $4.7 \pm 112.3$ & $17.7 \pm 10.4$ & $1.3 \pm 6.7$ \\
\hline Sangiovese $n$. & n.d. & $13.5 \pm 9.1$ & $1.6 \pm 8.6$ & $1.9 \pm 5.2$ \\
\hline Malvasia n. & $5.8 \pm 6.4$ & $2.4 \pm 7.7$ & $1.9 \pm 9.3$ & $2.9 \pm 13.6$ \\
\hline Negroamaro n. (Early) & $18.0 \pm 7.5$ & $28.0 \pm 9.2$ & $15.1 \pm 1.64$ & $4.2 \pm 14.7$ \\
\hline Uva di Troia n. & $17.9 \pm 11.3$ & $12.6 \pm 6.4$ & $5.0 \pm 9.7$ & $5.0 \pm 10.0$ \\
\hline Minutolo $b$. & $9.0 \pm 4.8$ & $15.1 \pm 5.9$ & $3.1 \pm 5.3$ & $6.3 \pm 8.7$ \\
\hline Aglianicone $n$. & $12.9 \pm 9.9$ & $11.3 \pm 9.6$ & $4.8 \pm 11.5$ & $5.5 \pm 7.8$ \\
\hline Fiano $b$. & n.d. & $22.3 \pm 12.3$ & $12.0 \pm 6.9$ & $9.4 \pm 6.3$ \\
\hline Susumaniello $n$. & $33.0 \pm 8.9$ & $26.1 \pm 10.4$ & $15.7 \pm 6.4$ & $14.2 \pm 6.9$ \\
\hline Mantonico $b$. & $13.9 \pm 10.1$ & $15.5 \pm 7.6$ & $11.3 \pm 10.2$ & $16.4 \pm 5.7$ \\
\hline Bombino b. & $52.2 \pm 13.5$ & $34.8 \pm 13.8$ & $29.3 \pm 15.3$ & $15.5 \pm 12.3$ \\
\hline Primitivo $n$. & n.d. & $18.2 \pm 7.8$ & $19.2 \pm 18.5$ & $28.0 \pm 6.8$ \\
\hline Greco b. & $27.1 \pm 12.0$ & $38.5 \pm 11.4$ & $24.8 \pm 12.6$ & $30.4 \pm 4.2$ \\
\hline Pecorino $b$. & $68.3 \pm 11.2$ & $75.3 \pm 9.0$ & $43.8 \pm 7.5$ & $37.5 \pm 8.8$ \\
\hline Aglianico n. & n.d. & $59.2 \pm 8.8$ & $44.1 \pm 9.9$ & $36.4 \pm 9.5$ \\
\hline
\end{tabular}

Table 3. Influence of training systems on shikimic acid content $(\mathrm{mg} / \mathrm{L} \pm \mathrm{CV} \%)$.

\begin{tabular}{lccccc}
\hline Wines 2006 & Simple curtain & Unilateral cordon & Bilateral cordon & Unilateral Guyot & Bilateral Guyot \\
Primitivo & $18.4 \pm 5.6$ & $15.0 \pm 4.8$ & $23.4 \pm 7.9$ & $16.5 \pm 5.3$ & $24.0 \pm 8.8$ \\
Malvasia & nd & $20.8 \pm 4.2$ & $23.5 \pm 6.6$ & $20.0 \pm 7.6$ & $24.6 \pm 5.1$ \\
\hline Montepulciano & $24.1 \pm 7.8$ & $19.8 \pm 5.0$ & $24.9 \pm 9.3$ & $22.1 \pm 8.0$ & $9.8 \pm 4.9$ \\
Negramaro & $9.5 \pm 4.4$ & $9.0 \pm 8.6$ & $10.4 \pm 8.7$ & $74.2 \pm 6.5$ & $11.3 \pm 4.3$ \\
\hline Cabernet s. & $72.9 \pm 6.1$ & $77.1 \pm 6.4$ & $83.0 \pm 8.8$ & $86.6 \pm 7.4$ \\
\hline
\end{tabular}

nd, not detected. 
acids composition of the Aglianico del Vulture produced in the same areas of Venosa and Rapolla. An aliquot of must of both areas have been transported and analysed during the fermentation at the Experimental Cellar of Barletta (CRA-UTV). It emerged (Figure 2) that the two samples of Venosa, inoculated with selected yeasts, showed no variations of the content of shikimic acid. Instead, the two samples of Rapolla have shown a significant increase in the content of shikimic acid up to 50 $\mathrm{mg} / \mathrm{L}$. To check whether such increase of shikimic acid was linked to the hydrolysis of its possible precursors, the juice of Aglianico of Venosa and Rapolla were subjected to different types of hydrolysis (basic, acid and enzymatic). The results showed no changes in the content of shikimic acid. Therefore, it remains to investigate the hypothesis of a possible microbial process responsible for the increase of shikimic acid. Recently (Tripathi et al., 2013) have shown that strains

Table 4. Average $\pm \mathrm{CV} \%$ of organic acid content in the Aglianico wines 2012.

\begin{tabular}{lccc} 
& & Rapolla area & Venosa area \\
Tartaric acid & $\mathrm{g} / \mathrm{L}$ & $2.78 \pm 11.4$ & $3.26 \pm 13.7$ \\
Malic acid & $\mathrm{g} / \mathrm{L}$ & $3.76 \pm 7.3$ & $1.02 \pm 6.4$ \\
\hline Shikimic acid & $\mathrm{mg} / \mathrm{L}$ & $113.0 \pm 5.5$ & $29.0 \pm 7.0$ \\
Lactic acid & $\mathrm{g} / \mathrm{L}$ & $0.32 \pm 8.8$ & $0.27 \pm 7.9$ \\
\hline Citric acid & $\mathrm{g} / \mathrm{L}$ & $0.34 \pm 12.6$ & $0.46 \pm 15.4$ \\
Succinic acid & $\mathrm{g} / \mathrm{L}$ & $2.14 \pm 6.9$ & $1.08 \pm 8.0$
\end{tabular}

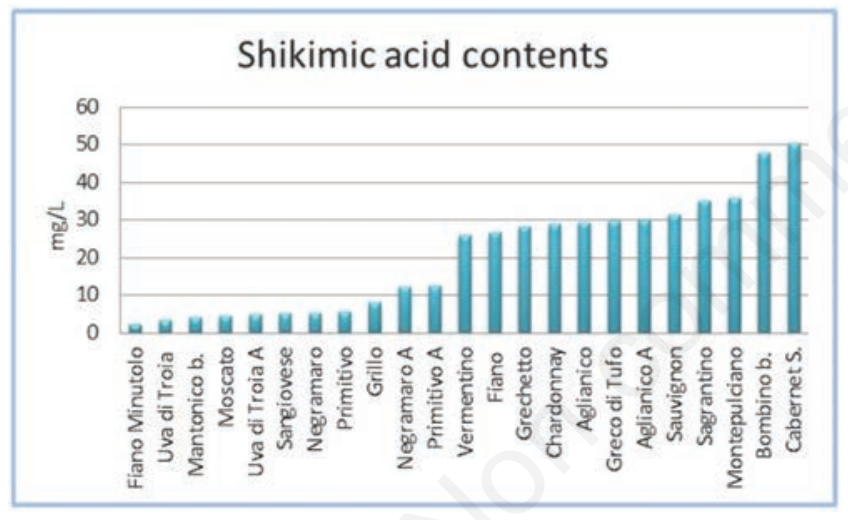

Figure 1. Shikimic acid contents in different grape varieties.

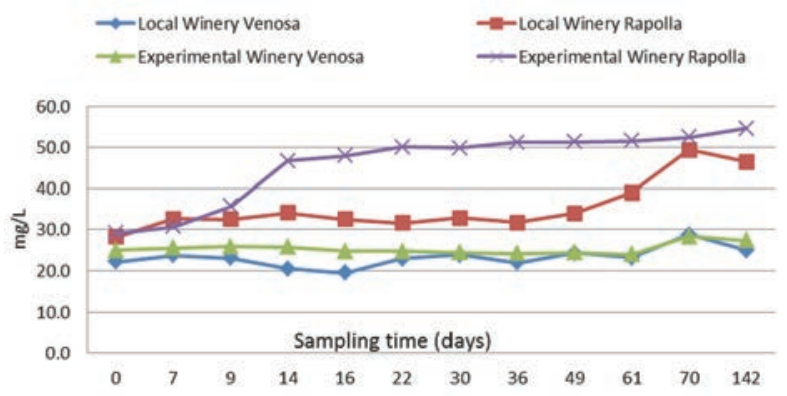

Figure 2. Shikimic acid kinetic of the Aglianico wines 2013. of bacterium Citrobacter freundii can produce $9.11 \mathrm{~g} / \mathrm{L}$ of shikimic acid from $20 \mathrm{~g} / \mathrm{L}$ of glucose in suitable conditions of fermentation. However, a preliminary microbial analysis of the fermenting must in a laboratory has not revealed the presence of this organism.

\section{Conclusions}

The shikimic acid, a precursor of aromatic amino acids and of flavonoids with a strong anti-inflammatory activity, was used as a varietal marker to distinguish Aglianico del Vulture from other varieties of black grapes of Apulia. The varietal dependence is confirmed by data related to the research project Vitivin-Valut. Primitivo and Negroamaro confirmed low shikimic acid content, as well as the Moltepulciano and Cabernet Sauvignon confirmed high values. However, shikimic acid decreases significantly during the ripening of the grapes and therefore its content in wines strongly depends on the time of harvest.

Moreover, three years of investigations have highlighted a surprising increase of shikimic acid during winemaking processes in a cru Aglianico del Vulture (Rapolla). Its content can exceed $100 \mathrm{mg} / \mathrm{L}$. Further investigations are necessary to explain this phenomenon.

\section{References}

El-Seedi HR, Ringbom T, Torsell K, Bohlin L, 2003. Constituents of Hypericum laricifolium and their cyclooxygenase (COX) enzyme activities. Chem. Pharm. Bull. 51:1439-40.

Giovannini L, Guidi A, Settimini L, Toti L, Mannari C, Flak WY, Bertelli A, 2008. Immunomodulatory activity of shikimic acid and quercetin, two compounds present in white wine, in a in vitro experimental model. Proc. 31st World Congress of Vine and Wine, June 15-20, Verona, Italy.

Ma Y, Sun JN, Xu QP, Guo YJ, 2000. Inhibitory effects of shikimic acid on platelet aggregation and blood coagulation. Acta Pharm. Sinica 35:1-4.

Ma Y, Xu QP, Sun JN, Bai LM, Guo YJ, Niu JZ, 1999. Antagonistic effects of shikimic acid against focal cerebral ischemia injury in rats sujected to middle cerebral artery thrombosis. Acta Pharm. Sinica. 20:701-4.

Paradiso F, Bolettieri D, Savino M, Latorraca M, Tamborra P, 2014. Lacide shikimique: un métabolite important pour le cépage Aglianico del Vulture. Proc. 3rd Edition of Wine Active Compounds, Oenoplurimédia, France.

Tamborra P, Esti M, 2010. Authenticity markers in Aglianico, Uva di Troia, Negroamaro and Primitivo grapes. Analyt. Chim. Acta 660:221-6.

Tamborra P, Piracci A, Coletta A, Esti M, 2009. Winemaking technique optimization for enancing aroma in Fiano wine. Atti Accademia Italiana della Vite e del Vino, Relazione n. 57, Tornata 26.

Tamborra P, Suriano S, Caputo AR, Toci AT, Giurato C, Pichierri A, Mazzone F, Antonacci D, 2012. Influenza delle tecniche culturali e del grado di maturazione sul contenuto di acido scichimico. Proc. 35th World Congress of Vine and Wine, June 2012, Izmir, Turkey.

Tripathi P, Rawat G, Yadav S, Saxena RK, 2013. Fermentative production of shikimic acid: a paradigm shift of production concept from plant route to microbial route. Bioprocess Biosyst. Eng. 36:1665-73.

Versini G, Mattivi F, Moser S, Pisoni A, Volunteer G, 2003. Shikimic acid quantification in experimental mono-varietal white wines produced in Italy. pp 166-169 in Proc. 7th Int. Symp. of Oenology, Lavoisier-Tec \& Doc, Paris, France. 